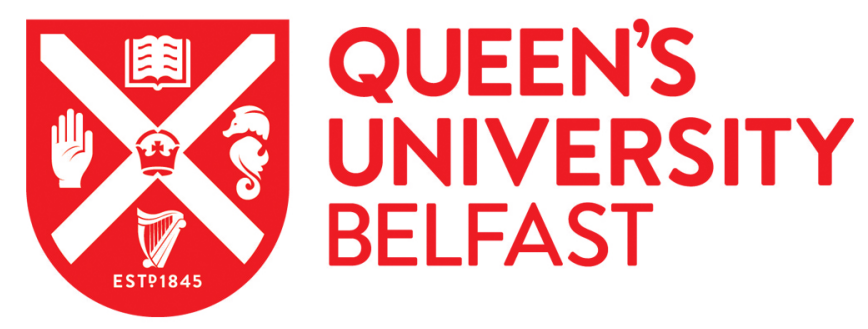

\title{
In touch to teach: Do nurse educators need to maintain or possess recent clinical practice to facilitate student learning?
}

Leonard, L., McCutcheon, K., \& Rogers, K. M. A. (2016). In touch to teach: Do nurse educators need to maintain or possess recent clinical practice to facilitate student learning? Nurse Education in Practice, 16(1), 148-151. https://doi.org/10.1016/j.nepr.2015.08.002

\section{Published in:}

Nurse Education in Practice

\section{Document Version:}

Peer reviewed version

\section{Queen's University Belfast - Research Portal:}

Link to publication record in Queen's University Belfast Research Portal

\section{Publisher rights}

(c) 2016 Elsevier Ltd. This manuscript version is made available under the CC-BY-NC-ND 4.0 license http://creativecommons.org/licenses/by$\mathrm{nc}-\mathrm{nd} / 4.0 /$, which permits distribution and reproduction for non-commercial purposes, provided the author and source are cited.

\section{General rights}

Copyright for the publications made accessible via the Queen's University Belfast Research Portal is retained by the author(s) and / or other copyright owners and it is a condition of accessing these publications that users recognise and abide by the legal requirements associated with these rights.

Take down policy

The Research Portal is Queen's institutional repository that provides access to Queen's research output. Every effort has been made to ensure that content in the Research Portal does not infringe any person's rights, or applicable UK laws. If you discover content in the Research Portal that you believe breaches copyright or violates any law, please contact openaccess@qub.ac.uk. 


\begin{abstract}
In recent years UK university-based nurse educators have seen a reduction in their responsibilities for nursing students' practice-based assessments. Many university-based nurse educators feel that this lack of input into students' clinical assessments leaves them open to criticism as they are perceived to be less "in-touch" with clinical practice and that their knowledge to teach nursing students is diminished as a result. This paper examines and debates some interpretations of the term "recent clinical practice" and challenges the misconception among many in the profession, as well as government and professional bodies, that university-based nurse educators require recent clinical practice to effectively teach students and enhance the student learning experience in the academic university setting.
\end{abstract}

\title{
Key words
}

- University-based nurse educators

- Recent clinical practice

- Clinical credibility

- Academic credibility

- Effective university teaching 


\section{Introduction}

Following investigations into poor care and neglect of patients at Mid Staffordshire NHS Trust in the United Kingdome (UK), The Francis Report (Francis, 2013) recommended there should be an increased focus in nurse education on the practical requirements of delivering compassionate care in addition to theory. This is reflective of a longstanding debate between the development of theoretical and practical knowledge to care for patients more commonly referred to as the 'theory-practice gap' (Price, Hastie, Duffy, Ness \& McCallum, 2011). The Willis Report (Willis, 2012) on nurse education identified the theory-practice gap' as the area where a discrepancy is perceived between theoretical study and learning in clinical settings (Andrews \& Roberts, 2003). Rolfe and Gardner (2006) highlighted that theoretical and clinical aspects of nursing practice are commonly separated and performed by separate and distinct groups of people often in separate and distinct locations. This is reflective of various models which have been developed to enhance theory-practice integration.

This renewed discourse between theory and practice comes at a time when nurse education in many countries, such as Australia, Canada, Ireland, the US, and the UK, has moved away from models of apprentice-like, hospital-based nurse training to university-led delivery of nurse education. However, such nursing education programmes involve a division of learning whereby students learn in clinical practice and in the university setting. This division makes the assumption that in university, students will have developed a theoretical knowledge base, critical thinking and decision-making skills which they then consolidate through the practical application of their knowledge in the clinical settings. In addition to 
applying theory, such clinical practice placements are believed to help students achieve the required learning outcomes and competencies according to regulatory body requirements for pre-registration education. A range of discourses as to how to best support nursing students in clinical practice have been suggested (McSharry, McGloin, Frizzell \& WintersO'Donnell, 2010; Price et al., 2011). While supporting students to learn is an important function for both educators and practitioners there is little consensus as to what constitutes appropriate support (Andrews \& Roberts, 2003) and these supporting roles are often carried out by separate and distinct groups of professionals. Mannix et al. (2006) highlight a need for an ongoing dialogue about such roles. It has been argued that the transition from vocational training of nursing to university-based education has produced tensions and lack of clarity in the identity, knowledge and practice of such roles (Adams, 2010; Adams, 2011). Spitzer and Perrenoud (2006) who in, analyzing the impact of the move of nursing to higher education ( $\mathrm{HE}$ ) across Europe, identified conflicting demands on university-based nurse educators to conduct research, to teach, and to maintain specialism in clinical practice. This paper examines the clinical and educational credibility that has arisen in relation to the changing roles of those responsible for nurse education. The nature of the knowledge needed to enhance nursing students' learning in clinical practice to help bridge the theorypractice gap is also debated. The paper seeks to continue dialogue by contending that expectations that nurse educators should be clinically credible or have recent clinical practice does not necessarily equate with enhancing student learning.

Clinical placements have allowed students the opportunity to work alongside experienced registered nurses who take on the role of supporting students in developing their 
competencies. In countries such as the UK, Canada and Finland these are known as mentors and similar to preceptor and "buddy" roles in Australia. Over the years a number of other roles have been introduced to support students in practice such as clinical teachers and lecturer practitioners in the UK (Brown, 2006; Smith \& Allan, 2010) similar to clinical facilitators in Australia (Mannix et al., 2006) and clinical tutors in the USA. These roles are seen as offering additional support to that from mentors, preceptors or buddies. In the UK and other countries university-based nurse educators (lecturers) provided an additional supporting "link lecturer" role.

In the UK recent focus has been on the role of mentors, with the Nursing and Midwifery Council (NMC) mandatory requirement that students on pre-registration nursing education programmes must be supported and assessed by mentors in the clinical setting (NMC, 2008). Mentors are now required to develop, assess and "sign off" students as achieving NMC defined standards for learning in practice to be eligible for professional registration (NMC, 2008). The assumption is that mentors have the knowledge to teach and support students; this reflects a concept of competent practitioners "transferring" knowledge to students through demonstration and example. However, Edmond (2000) and Carr (2008) argued that mentors have heavy workloads and often feel unsupported or unprepared for the demands of the role. Goodman (2013) suggested that mentors in many clinical areas are under pressure due to increased workloads which is detrimental to the student learning experience. While mentors are expected to support students' learning in practice, they may not have the necessary support or training to do so. This sentiment was endorsed by Bennett and McGowan (2014) whose recent study reported that mentors believed they lacked experience and preparation to effectively assess students in practice and identified 
their need for support. Without the appropriate resources to support students in practice, tensions in the mentorship role could perpetuate a theory-practice gap (McBrien, 2006).

In response to such issues, and in anticipation of the NMC 2008 requirements, the Practice Education Facilitator (PEF) roles were introduced in Northern Ireland (NI), between 20092010 to support mentors. Similar roles having been introduced in other parts of the UK and the Republic of Ireland. In NI, PEFs are registered nurses employed and based in clinical areas rather than in the university sector, who have undertaken study in educational theory such as a Post-graduate Certificate in Teaching and Learning.

Prior to this, the dominant model was that of university-based nurse educators (nurse lecturers) supporting mentors and students in practice in a "link lecturer role" which included formative support and end-of-year summative assessment of student practice, in partnership with the mentor. However as Ousey and Gallagher (2011) highlight such a role was often itself is ad hoc, transitory and lacking in clarity. The introduction of the PEF role has led to a further lack of clarity around the role of university-based educators in supporting and developing students' clinical practice. Smith and Alan (2010) claim that these new roles reinforce a split between theory and practice. This change may also reinforce an earlier assertion by Maslin-Prothero (2001) that the clinical practice role of nurse lecturers has been lost, enhancing suggestions by Thompson and Watson (2001) that it is an entirely academic role. O'Driscoll et al. (2010) suggested that this has diminished the lecturers' connection with practice and detached academic education from clinical practice.

Carr (2007) found that the longer nurse lecturers worked in university, the likelihood of maintaining clinical practice expertise was significantly reduced. Mallik and Hunt (2007) also suggested that nurse lecturers have weak links to practice and as they spend less time in the 
clinical setting they become out of touch with current clinical practice (Ousey \& Gallagher, 2010). This notion of being "in touch" is not defined but is often equated with visibility in the practice areas. McNamara (2009) argued that it has led to accusations that nurse lecturers cannot fully appreciate and are insensitive to the realities of clinical nursing practice in today's society. This implies that nurse lecturers' professional knowledge to teach is informed and developed by practice in the clinical area. However, while clinical practice may enhance the knowledge of the nurse lecturer it does not necessarily ensue that this will translate into teaching. In addition the knowledge gained may not equate with the knowledge required by the students to practice.

\section{The knowledge base and professional identity of nurse educators}

Professional identity has been defined as an immersion in the subject knowledge and practice of the profession (Hegarty, 2000). This is reflected in the UK government paper "Modernising Nursing Careers" (DoH, 2006; Health, 2006) which emphasised the importance of health professionals developing their knowledge and skills to improve the quality of healthcare (Gibbs, 2011). However a dichotomy arises for nurse lecturers, as to whether the attainment, maintenance and development of that professional knowledge should be clinical or educational. Morgan (2012) claims that an inherent part of the nurse lecturer role is keeping up to date with nursing developments as these are a crucial component of teaching. Barrett (2007) argued that the view that nurse lecturers need to maintain a clinical role has been fuelled by successive governments and professional bodies. A further suggestion by Fisher (2005) that there has been pressure to recruit nurse educators who possess both practical and current nursing experience. This is also reflected 
in the "Making a Difference" document which emphasised that students should be taught by those with recent practice and experience of nursing (DoH, 1999). The contemporaneous nature (or indeed the definition) of such "recent practice and experience" is not defined, but there is an assumption that clinical practice will enhance the knowledge of the lecturer in teaching students. This view is summarised by Williams and Taylor (2008:900) who argued that nurse educators should undertake "clinical practice to facilitate their clinical confidence and ability to teach the theory and practice of nursing". These perceptions have given rise to discourses and assumptions on clinical competency and credibility (McSharry et al., 2010) and are reflected in the NMC requirement that nurses, including nurse lecturers demonstrate continuing evidence of competency. Similar expectations for nurse educators are documented in the US NLN competencies (NLN, 2012) which also suggest that more clinical expertise is needed by nurse educators.

Maslin-Prothero (2001) suggested that it is important for nurse lecturers to maintain a clinical role but such a role assumes clinical competency and credibility. Furthermore, Cave (2005) suggested if nurse educators do not maintain their clinical ability they will struggle to bridge the theory-practice gap. However, others such as Humphreys et al. (2000) and Fisher (2005) have suggested that there is a lack of clarity on such terms as clinical credibility and clinical competence. There are also assumptions that these are a necessary element of the nurse lecturers' knowledge to teach.

While there may be expectations from professional bodies requiring nurses, including nurse educators, to demonstrate continuing evidence of competency and to ensure that their knowledge is maintained and relevant (Gibbs, 2011), the nature of such knowledge is open to interpretation. Wray and Wild (2011) acknowledge that in the UK the NMC requirements 
are open to interpretation, yet appear to interpret it as practicing within the clinical setting, whereas the NMC suggest it as just one way that nurse lecturers can take part in learning activities to maintain their knowledge and competency and performance as a teacher (NMC, 2008). However, there is no specific mention of clinical practice or what such time in practice should involve. Gibbs (2011) makes the point that even if there is learning in practice it is not evident as to how the individual will apply such learning. Overall there appears to be a lack of evidence to support the theory that spending time in clinical practice would equate with the development of the nurse lecturer's competence or performance in either nursing or teaching practice. While clinical practice may enrich the knowledge of the nurse lecturer it is not the only way in which the nurse lecturer can build and maintain their knowledge. The knowledge and skills to teach and support students' learning do not necessarily equate with clinical knowledge.

\section{Perspectives on clinical practice}

It has been suggested that time spent in the clinical setting will enhance teaching and help to bridge the perceived theory-practice gap (Cave, 2005; Griscti, Jacono \& Jacono, 2005). However there is a diversity of perspectives as what such time should involve. Some suggest that time spent in the clinical setting should take the form of direct patient care and support for staff and mentors (Carr, 2007; Elliott \& Wall, 2008). However as Fourie et al. (2005) argued the management of a clinical case load is neither a measure of credibility of either clinical practice or the ability to teach.

A further assumption is that nursing practice is homogenous, yet nurses' roles are multifaceted requiring a diversity of skills and knowledge. As Ousey and Gallagher (2010) 
discussed credibility can only extend to the role that the nurse undertakes and given the diversity of nursing roles it would be unrealistic to expect nurse lecturers to maintain expertise in the wide range of nursing practice. Just as the skills and knowledge required to nurse in acute critical care, differ from those needed to practice in a palliative care setting so does the knowledge and skills of the nurse lecturer. Rolfe (2007) proposed that the nurse educator's role should be one of facilitation to do nursing rather than the actual practice of nursing while Carter (2009) states the art of teaching is the central function of nurse lecturers.

In the US this is reflected in a position statement from the US National League for Nursing which emphasises the importance of lifelong learning for nurse educators, with an emphasis on learning about education as well as clinical (NLN, 2012).

Any discussion about teaching and learning must consider the nature and debate around knowledge. Schon's (1990) well-known theory of knowledge described the complexity of the training for different professions, differentiating between different types of knowledge, such as knowing about and in knowing how to such as in skills or competence. Little and Milliken (2007) suggested that being perceived as a clinical expert will not automatically make that individual a good teacher of their specialised subject matter. While clinical practice may add to the experience and knowledge of the nurse lecturer such clinical expertise is not necessarily the same as educational knowledge. Ousey and Gallagher (2010) highlighted that pivotal to the development of students is the educational knowledge that lecturers hold while Hegarty (2000) argues that teaching knowledge includes understanding pedagogy and that there is a different relationship between the educator and the knowledge required to teach and the knowledge needed for clinical practice. Conway and 
Elwin (2007) cautioned than an emphasis on the clinical knowledge of the nurse educator risks negating or undermining educational expertise.

A variety of learning theories influence views on education but can be broadly grouped under what Uys and Gwele (2005) refer to as the either the essentialist or progressive view of knowledge development. The essentialist view assumes that there is core body of knowledge and skills that must be passed on to the student. This is what Weis et al (2006) refers to as the transmission/acquisition model of education. Gallagher (2004) highlights this as one assumption of knowledge within the discourses of practice in nursing and that often the language used assumes that knowledge exists is "out there" and can be transmitted by the teacher through instruction, demonstration and practice.

Discussion on clinical credibility makes the assumption that the lecturer's responsibility as 'experts', is simply to transmit their knowledge to learners, students then need to apply this learning to practice. This reflects a somewhat simplistic view of learning which assumes that learning occurs when knowledge is conveyed from an informed source to a less-knowing audience (Ng \& Tan, 2009). In today's society, with the increasing use of technology and the internet in education, a knowledge source can take many guises, not simply the traditional, large lecture-theatre scenario.

In the discourse of being "in touch" through clinical practice, there can be a risk that it limits education to replication and transmits only what is known rather than the facilitation and development of new knowledge to challenge, transform and extend practice. The justification of competence to teach on the basis of being in clinical practice and therefore "in touch", are open to the challenge that such individuals can be also "out of touch" from 
the theoretical aspects of nurse education and thus risk a widening of the theory-practice gap. If such issues are to be resolved there needs to be stronger partnerships between those involved in clinical practice education and those, such as university-based lecturers, who bring an academic, educational perspective to nurse education. Darbyshire (2011) asserted that the business of nurse educators is more than the mere transmission of knowledge or teaching of skills but should also be transformative. Fraser (2007) suggested transformative models of professional learning provide strong links between theory and practice by construction of new knowledge and its application in different situations.

\section{Conclusion}

University-based nurse educators need to therefore continue to provide educational input and support for students and staff involved in clinical practice education. There needs to be clearer structures - perhaps directed by the professional bodies - for the support and development of clinical-based staff involved in clinical practice education, to prevent practice learning from becoming mere uncritical repetition of practices observed during clinical placements. However that input may not necessarily mean that university-based lecturers need to undertake routine clinical practice to maintain professional and academic credibility in the university teaching environment.

The introduction of clinical education support roles (such as PEFs or "buddies") is welcome because they can offer additional support to students learning in practice. Co-operation between lecturers and those in clinical education support roles should increase and nurture the development of better skilled, knowledgeable, adaptable, and competent graduate 
practitioners. This is supported by Grealish and Smale (2011) who propose that when there is collaboration between all stakeholders there is a greater likelihood that a positive learning experience for students in the clinical environment - a goal which all nurse educators will aspire to.

Word count: 2919

Conflict of interest statement: none

\section{$\underline{\text { References }}$}

Adams, R. 2010. Exploring dual professional identities, the role of the nurse tutor in

Higher education in the UK: role complexity and tensions. Journal of Advanced Nursing, 67, 8.

Adams, R. 2011. Exploring dual professional identities, the role of the nurse tutor in higher education in the UK: role complexity and tensions. Journal of Advanced Nursing, 67, 884-892.

Andrews, M. \& Roberts, D. 2003. Supporting student nurses learning in and through clinical practice: the role of the clinical guide. Nurse Education Today, 23, 474-481.

Bennett, M. \& McGowan, B. 2014. Assessment matters-mentors need support in their role. British Journal of Nursing, 23, 454-458.

Brown, S.J. 2006. The experiences of lecturer practitioners in clinical practice. Nurse Education Today, 26, 601-608.

Carr, G. 2007. Changes in nurse education: being a nurse teacher. Nurse Education Today, 27, 893899.

Carr, G. 2008. Changes in nurse education: delivering the curriculum. Nurse Education Today, 28, 120-127. 
Carter, S. 2009. Renewing pride in teaching: using theory to advance nursing scholarship. Nurse Education in Practice, 9, 119-126.

Cave, I. 2005. Nurse teachers in higher education--without clinical competence, do they have a future? 1994. Nurse Education Today, 25, 646-651

Conway, J. \& Elwin, C. 2007. Mistaken, misshapen and mythical images of nurse education: creating a shared identity for clinical nurse educator practice. Nurse Education in Practice, 7, 187-194.

Darbyshire, P. 2011. The business of nurse educators in troubled times. Nurse Education Today, 31, 723-724.

DoH. 1999. Making a difference: strengthening the nursing, midwifery and health visiting contribution to health and healthcare. Department of Health, UK: [Online] Available from: http://webarchive.nationalarchives.gov.uk/+/www.dh.gov.uk/en/Publicationsandstatistics/Publicati ons/PublicationsPolicyAndGuidance/DH 4007977 [Accessed: 6th Aug 2014].

DoH. 2006. Modernising Nursing Careers: Setting the direction. UK: Health, D.o.H [Online] Available from: http://www.dhsspsni.gov.uk/modernising nursing careers-2.pdf [Accessed: 6th Aug 2014].

Edmond, C.B. 2000. A new paradigm for practice education. Nurse Education Today, 21,:251-259.

Elliott, M. \& Wall, N. 2008. Should nurse academics engage in clinical practice? Nurse Education Today, 28, 580-586.

Fisher, M.T. 2005. Exploring how nurse lecturers maintain clinical credibility. Nurse Education in Practice, 5, 21-29.

Fourie, W.J., McDonald, S., Connor, J. \& Bartlett, S. 2005. The role of the registered nurse in an acute mental health inpatient setting in New Zealand: perceptions versus reality. International Journal of Mental Health Nursing, 14, 134-141.

Francis. 2013. Report of the Mid Staffordshire NHS Foundation Trust Public Inquiry. [Online] Available from: http://www.midstaffspublicinquiry.com/report [Accessed: 6th Aug 2014]. 
Fraser, C., Kennedy, A., Reid, L. \& McKinney, S. 2007. Teachers' continuing professional development: contested concepts, understandings and models. Journal of In-Service Education, 33, 153-169.,

Gallagher, P. 2004. How the metaphor of a gap between theory and practice has influenced nursing education. Nurse Education Today, 24, 263-268.

Gibbs, V. 2011. An investigation into the challenges facing the future provision of continuing professional development for allied health professionals in a changing healthcare environment. Radiography, 17, 152-157.

Goodman, B. 2013. "What are nurse academics for?" Intellectual craftsmanship in an age of instrumentalism. Nurse Education Today, 33, 87-89.

Grealish, L. \& Smale, L.A. 2011. Theory before practice: implicit assumptions about clinical nursing education in Australia as revealed through a shared critical reflection. Contemporary Nurse, 39, 5164.

Griscti, O., Jacono, B. \& Jacono, J. 2005. The Nurse Educator's clinical role. Journal of Advanced Nursing, 50, 84-92.

Health, D.o. 2006. Modernising Nursing Careers: Setting the direction. Health, D.o. [Online] Available from: http://www.dhsspsni.gov.uk/modernising nursing careers-2.pdf [Accessed: 6th Aug 2014]. Hegarty, S. 2000. Teaching as a Knowledge-based Activity. Oxford Review of Education, 26,451-465. Humphreys, A., Gidman, J. \& Andrews, M. 2000. The nature and purpose of the role of the nurse lecturer in practice settings. Nurse Education Today, 20,311-317.

Little, M.A. \& Milliken, P.J. 2007. Practicing what we preach: balancing teaching and clinical practice competencies. International Journal of Nurse Education Scholarship, 4, 1548.

Mallik, M. \& Hunt, J.A. 2007. Plugging a hole and lightening the burden: a process evaluation of a practice education team. Journal of Clinical Nursing, 16,1848-1857.

Mannix, J., Faga, P., Beale, B. \& Jackson, D. 2006. Towards sustainable models for clinical education in nursing: An on-going conversation. Nurse Education in Practice, 6, 3-11. 
Maslin-Prothero, S.E. \& Owen, S. 2001. Enhancing your clinical links and credibility: the role of nurse lecturers and teachersin clinical practice. Nurse Education in Practice, 1, 189-195.

McBrien, B. 2006. Clinical teaching and support for learners in the practice environment. British Journal of Nursing, 15, 672-677.

McNamara, M.S. 2009. Nursing academics' languages of legitimation: a discourse analysis.

International Journal of Nursing Studies, 46, 1566-1579.

McSharry, E., McGloin, H., Frizzell, A.M. \& Winters-O'Donnell, L. 2010. The role of the nurse lecturer in clinical practice in the Republic of Ireland. Nurse Education in Practice, 10, 189-195.

Ng, P.T. \& Tan, C. 2009. Community of practice for teachers: sensemaking or critical reflective learning? Reflective Practice, 10, 37-44.

NLN. 2012. Outcomes and Competencies for Graduates of Practical/Vocational, Diploma, Baccalaureate, Master's Practice Doctorate, and Research NLN Bookstore. National League for Nursing.

NMC. 2008. Nursing and Midwifery Council: Standards to support learning and assessment in practice. [Online] Available from: http://www.nmc-uk.org/Documents/NMC-Publications/NMCStandards-to-support-learning-assessment.pdf [Accessed: 6th Aug 2014].

O'Driscoll, M.F., Allan, H.T. \& Smith, P.A. 2010. Still looking for leadership--who is responsible for student nurses' learning in practice? Nurse Education Today, 30, 212-217.

Ousey, K. \& Gallagher, P. 2010. The clinical credibility of nurse educators: time the debate was put to rest. Nurse Education Today, 30, 662-665.

Price, L., Hastie, L., Duffy, K., Ness, V. \& McCallum, J. 2011. Supporting students in clinical practice: pre-registration nursing students' views on the role of the lecturer. Nurse Education Today, 31, 780784.

Rolfe, G. 2007. Nursing scholarship and the asymmetrical professor. Nurse Education in Practice, 7, 123-127. 
Rolfe, G. \& Gardner, L. 2006. Education, philosophy and academic practice: nursing studies in the posthistorical university. Nurse Education Today, 26, 634-639.

Schon, D.A. 1990. Educating the Reflective Practitioner: Toward a New Design for Teaching and Learning in the Professions (The Jossey-Bass Higher Education series), San Francisco, John Wiley \& Sons.

Smith, P. \& Allan, T.H. 2010. "We should be able to bear our patients in our teaching in some way": theoretical perspectives on how nurse teachers manage their emotions to negotiate the split between education and caring practice. Nurse Education Today, 30, 218-223.

Spitzer, A. \& Perrenoud, B. 2006. Reforms in Nursing Education Across Western Europe: From Agenda to Practice. Journal of Professional Nursing, 22, 150-161.

Thompson, D.R. \& Watson, R. 2001. Academic nursing--what is happening to it and where is it going? Journal of Advanced Nursing, 36, 1-2.

Uys, L. \& Gwele, N. 2005. Curriculum Development in Nursing: process and innovation. London and New York: Routledge.

Weis, L., McCarthy, C. \& Dimitriadis, G. 2006. Ideology, Curriculum, and the New Sociology of Education: Revisiting the Work of Michael Apple. Routledge, New York and London.

Williams, A. \& Taylor, C. 2008. An investigation of nurse educator's perceptions and experiences of undertaking clinical practice. Nurse Education Today, 28, 899-908.

Willis, P. 2012. Quality with compassion: the future of nurse education. London: [Online] Available from: http://www.williscommission.org.uk/recommendations [Accessed: 6th Aug 2014].

Wray, J. \& Wild, K. 2011. Maintaining practice: Challenges for nurse educators? Nurse Education in Practice, 11, 4-5. 